\title{
Getting Evidence-Based Teaching Practices into Mathematics Departments: Blueprint or Fantasy?
}

\author{
Robert Reys
}

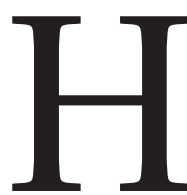

ow do you teach mathematics in your college classes? Are undergraduate classes taught the same as graduate classes? Do you teach mathematics as you were taught? Are your instructional practices aligned with what research says about how students learn mathematics? Do you use evidence-based instructional practices? That is, does evidence exist that your instructional practices help students learn the mathematics you are teaching? How often do you exchange ideas about teaching mathematics with colleagues? The purpose of this paper is to encourage discussion among college faculty about effective instructional practices with the intent of improving the teaching and student learning of mathematics.

\section{The Need to Improve Mathematics Teaching}

Since the days of E. H. Moore and his 1902 presidential address to the AMS there have been many calls for improved teaching of mathematics [1]. More recently David Bressoud in the MAA Launchings [2] shares some ways that physicists have worked to utilize evidence-based teaching methods in their classes. Bressoud also provides resources that represent multiple perspectives from mathematicians engaged in the scholarship of teaching. Yet, despite the desire to promote better mathematics learning in STEM courses and the growing body of evidence-based research that has implications for teaching practices, changing

Robert Reys is Curators' Professor Emeritus of Mathematics Education at the University of Missouri-Columbia. His email address is reysr@missouri . edu.

DOI: http://dx.doi.org/10.1090/noti1018 collegiate instructional practices has been slow and does not happen easily [3].

In September 2011 the Association of American Universities announced a five-year initiative to improve the quality of undergraduate teaching and learning in science, technology, engineering, and mathematics (STEM) at its member institutions. In February 2012 the President's Council of Advisors on Science and Technology (PCAST) issued a report [4] that forecast the need for producing "1 million more college graduates in STEM fields" during the next decade. Among other things, the report noted the important role that college mathematics courses play in either opening or closing the doors to different STEM fields. To address this issue, the PCAST report called for more research into the best ways to teach and learn mathematics and urged "widespread adoption of empirically validated teaching practices" by STEM faculty in higher education. It also recommended the launch of "a national experiment in postsecondary mathematics education to address the mathematicspreparation gap."

In June 2012 the National Science Foundation issued a Dear Colleague Letter for Widening Implementation and Demonstration of Evidencebased Reforms (WIDER) calling for proposals. The program is intended to promote improvement in undergraduate STEM instructional practices and bring to scale successful instructional practices within and across departments. This is just one of the initiatives designed to stimulate greater knowledge of and widespread use of evidence-based instructional practices. This initiative provides mathematics departments an opportunity to focus on teaching practices. The visual image of most collegiate-level mathematics courses (regardless 
of its accuracy) is a professor writing on a black/ whiteboard with his/her back to the class while students are copying feverishly and others have their hand raised but their questions going unanswered [5]. There are many factors that influence the instructional methods faculty members employ in their teaching practices. Probably the single most influential factor impacting how teachers teach is their prior experience as a student [6]. Stigler and Hiebert claim that breaking away from the cultural model of mathematics teaching that is so prevalent in the United States, typically lecture and note taking, is a major challenge. In the research related to evidence-based teaching in STEM undergraduate courses, it is worth noting that the focus has been almost exclusively on science-related courses [7], [8]. Despite the work of R. L. Moore and the legacy of the Moore method, it can be argued that inquiry-based learning is much more prevalent in science courses than in mathematics courses at the undergraduate level [9], [10], [11]. Perhaps opportunities to engage in laboratory environments provides experiences that engage learners and promotes more inquiry-based practices in science and engineering, whereas mathematics is too often viewed as a spectator sport; i.e., show me what to do or tell me how to do it, and I will memorize and practice the procedures. Even though there have been many calls by professional organizations to make the learning of mathematics a sense-making activity (National Council of Teachers of Mathematics, Mathematical Association of America, American Mathematical Society), for many college students mathematics learning is viewed as assuming a passive rather than an active role in learning.

\section{Challenges Related to Changing Instructional Approaches}

What are some of the hurdles to be cleared in promoting evidence-based change in teaching practices in collegiate mathematics classes? Here are a few broad challenges:

- We tend to teach as we have been taught. If lecture is the primary model experienced for learning mathematics, as Stigler and Hiebert suggest, it is difficult to break this cycle. Since professors teaching mathematics courses were successful in learning mathematics via a lecture method, it is difficult for them to relate to learning difficulties of their students. A frequently voiced sentiment is, "if it ain't broke, don't fix it." However, other people, particularly those outside mathematics, who cite the high rate of attrition in college mathematics courses argue that "actually it is broke" and there are some fundamental problems regarding the learning and teaching of mathematics that need to be addressed.

- Doctoral programs in mathematics are heavily weighted toward research, with limited systematic attention to teaching. In order to do original research in mathematics, one needs to delve deeply into a topic within a discipline. Completion of a Ph.D. in mathematics requires extensive research that focuses on mathematics, and thus few doctoral programs in mathematics have specific requirements regarding competence in teaching. ${ }^{1}$ The goal of covering many chapters each semester still exists, and fixed pacing requirements often make it difficult for instructors to break away from lectures and engage their students in open discussions about the mathematical concepts being examined. Furthermore, heavy emphasis on mathematics research leaves little time for TAs to focus on evidenced-based instructional practices. In fact, Project $\mathrm{NExT}^{2}$ was established in part to help provide some support for further development of teaching skills by new faculty members in mathematics departments.

- The climate and environment of the department/ college/institution provides a powerful context to either support or discourage emphasis on good teaching. Some research suggests this is the single most important factor inhibiting change in teaching practices [12], [13]. For example, does scheduling of large classes with several hundred students limit the use of evidence-based instructional options? Are specific service courses, such as business calculus or linear algebra, viewed as service courses? If so, it may discourage a focus on inquiry when a course is supposed to help students learn specific skills. Does the chair/dean/chancellor encourage and value good teaching? Are their values made clear? Are there support systems for helping faculty learn about evidence-based research related to effective teaching practices? Is there motivation/incentive to engage in learning about different instructional models?

- The reward system in comprehensive researchoriented institutions favors faculty members who gain national visibility via their research and scholarship rather than based on the quality of their teaching. An average or below-average teacher may be promoted because of a sterling record of scholarship. However, it is rare (virtually

\footnotetext{
$\overline{{ }^{1} \text { Nearly fifty years ago while I was a doctoral student, }}$ I taught college algebra and calculus for two years as a teaching assistant in a mathematics department at a research university. During that time the extent of instructional support was limited to giving the TAs a book and specific expectations about what chapters to cover. We did not know what classes we were assigned to teach until the night before classes started! Thank goodness progress has been made and support for TAs has improved in mathematics departments since I was a TA.

${ }^{2}$ Project NExT (New Experiences in Teaching) is a program founded over twenty years ago and is sponsored by the Mathematical Association of America. For more information see http: //archives . math . utk . edu/projnext/.
} 
impossible) for a faculty member who is a great teacher but has done little research in mathematics to be promoted in a research-oriented institution. Thus, the argument offered by Earnest Boyer [14] more than twenty years ago for rewarding the scholarship of teaching has not made much headway.

- Faculty members face pressures throughout their careers but may react differently depending on the stage of their career. While publication pressure is usually the heaviest early in their careers, once that hurdle is cleared faculty members may focus attention elsewhere, including teaching [15]. So while posttenured faculty members may be interested in teaching, their instructional approaches may have become so entrenched that significant change is very difficult [16]. On the other hand, some senior faculty members choose to give more attention to improving teaching practices. This has been sparked in some cases by calls for collaboration between higher-education faculty and K-12 school systems (e.g., NSF Math Science Partnerships).

- Institutions of higher education have created new types of faculty appointments to address teaching. This may be viewed as a blessing or a curse. New faculty tracks have been created for specialized roles (e.g., adjunct, clinical, visiting, fixed-term, nonregular, and postdocs). Many of these appointments are designed to address the teaching needs of institutions, so it seems reasonable that these people would be highly motivated to learn about and use evidence-based teaching practices [17], [7]. However, hiring "others" to focus on teaching, may in fact decrease interest by faculty in tenuretrack positions to explore ways to improve their teaching.

In an effort to gain information about what some institutions know about the teaching practices employed in their mathematics classes, I contacted a department chair and a provost at two research-oriented institutions. I know both of these people well. I felt I could be honest with them and that they would be honest in their responses.

\section{Questions Asked and What Was Learned from} Two Institutions

Here is how I situated the discussion: I am trying to learn about the instructional practices being used in undergraduate mathematics classes at your universities. I want to identify issues and challenges that would most likely be encountered in gathering information about instructional practices used by your mathematics faculty members teaching undergraduate courses. I then asked:

- Do you regularly collect information about instructional practices used in teaching your undergraduate mathematics courses at your institution? (This would include teachers who are graduate students as well as adjunct and regular faculty members.)
Neither institution collected any data on teaching practices. The provost said their institution collects information to support a state mandate to provide an "Institution Effectiveness Plan", but this amounted to collecting course syllabi that highlight content. While some of these syllabi provide clues about instructional practices, there is no specific requirement or expectation that instructional practices be addressed. While each institution gathers course evaluations from students, they have no current structure that systematically collects information about teaching practices nor do they have any mechanism in place that communicates information about best or effective teaching practices to their faculty members.

More specifically, the mathematics department chair said: "No, we currently do not have such information. The department is initiating ways to collect such information in a more formal manner than 'coffee room' chatter about what somebody did in class. We are planning to have a department 'retreat' (a couple of hours) this year where interested faculty will share their encouraging teaching practices, and this is actually a pretty big step for us."

- What do you think would be the most significant barriers in getting faculty members to participate in efforts to learn about evidence-based instructional practices?

Each of the administrators mentioned lack of time and uncertainty of the perceived value/ importance of the activity. The mathematics department chair went on to say:

"Many mathematicians are so 'involved in their research' that their teaching is something they do; there is a belief that teaching is inherently good (they teach the way they were taught and that IS GOOD, by definition) - the students are ill-prepared and that causes the problem. The department culture about teaching is the most significant barrier as I see it. Promotion requires publications/grants, etc.; teaching is regarded as good unless there is some major issue that surfaces...good teaching practices rarely have an important role in the process. So, the culture has to change; it must respect more than traditional thinking about research contributions.

"I have also found that many research mathematicians have really good ideas about teaching and learning-and they practice these regularly, but they really don't share them with colleagues in part because they don't have an opportunity to do so. As the culture changes and instruction is understood to become part of the equation for advancement, faculty will want to be better teachers and share what they do." 
- Are there incentives to systematically collect information about teaching practices used by mathematics faculty members?

The provost suggested an appeal to professional responsibility. She also addressed the importance of selling this need to top-level administrators and convincing them how this information would be useful to them in making policy decisions. She said the data collection would need to include all STEM disciplines and not be limited to a single department. Furthermore, any such survey would need to be free of implied or stated value judgments regarding particular instructional practices. The need to avoid any bias with regard to teaching practices was reiterated by the mathematics department chair. In addition, the mathematics chair said:

"In reality, there are probably not any incentives. The culture has to change. It is rare that a person will get a good raise because they were a good teacher. We give a lot of lip service to good teaching, but there is no concerted effort to encourage or reward it in the department."

This quote prompted a reviewer of this paper to say, "We need a culture that encourages faculty to think about the effectiveness of their teaching, to share their personal insights, and to provide support that enables faculty to adopt easily implementable ideas and helps faculty monitor the effectiveness of what they are doing." I say, Amen! Although, I don't think we should limit ourselves to "easily implementable ideas", as some of the evidence-based practices may not be easy to implement.

\section{Where to from Here?}

This discussion provides a limited glimpse about mathematics teaching, including perspectives from administrators from a Carnegie doctoral/ research university and the other from a research university (high research activity). Yet these perspectives represent only two of more than 3,000 four-year institutions of higher education and none of the nearly 2,000 two-year institutions. This discussion suggests that structuring a framework that will provide accurate profiles of the current teaching practices in mathematics courses in various institutions is a big challenge. Using that information to inform faculty members in institutions of higher education about evidencebased teaching practices and helping to stimulate systematic change in teaching practices are likely to pose a far more demanding challenge.

The stakes of not doing everything possible to improve mathematics teaching and learning are high. Millions of students are taking courses in mathematics at institutions of higher education this year. Whether the courses are remedial, satisfying a general education requirement, calculus or beyond, there is increasing interest and pressure to make learning of mathematics meaningful and to help students make sense of whatever mathematics is being learned. While students have a responsibility to seek understanding of the mathematics, faculty members have a responsibility to utilize evidence-based teaching practices to help facilitate mathematics learning.

So what might a mathematics department do? One valuable first step would be to have an open and frank discussion about teaching among members of the department. This might include: addressing some of the opening questions, sharing teaching approaches and techniques that professors use, visiting and observing other professors as they teach, learning more about how people learn, and examining evidence-based instructional practices that have been shown to be successful. Any or all of the above might be eye opening and intellectually stimulating and perhaps most importantly be recognition that the department is serious about improving the teaching and learning of mathematics at its institution.

As the department chair interviewed said, "The culture has to change." The big question is how and whether his statement reflects a blueprint or fantasy for his institution and thousands of other mathematics departments throughout the U.S. My hope is that this article will stimulate some discussion about your departmental culture and help bring teaching and learning of mathematics to the forefront.

\section{References}

1. A. H. SCHOENFELD, When good teaching leads to bad results: The disasters of "well taught" mathematics courses, Educational Psychologist 23 (1988), 145-166.

2. D. BRESSOUD, MAA Launchings (September 17, 2012). See http://launchings.blogspot. com/2012/07/ 1earning-from-physicists.htm7; http:// 1aunchings.blogspot.com/2012/08/barriersto-change.htm 1

3. A. E. Austin, M. Connolly, C. Pfund, D. L. GillianDANiEL, and R. MATHIEU, Preparing STEM doctoral students for future faculty careers, in R. G. Baldwin (ed.), Improving the Climate for Undergraduate Teaching and Learning in STEM Fields, Jossey-Bass, San Francisco, CA, 2009.

4. President's Council of Advisors on Science and Technology-PCAST (August 29, 2012), Engage to excel: Producing one million additional college graduates with degrees in science, technology, engineering, and mathematics. See http://www. whitehouse.gov/ sites/default/files/microsites/ostp/pcastengage-to-excel-final_2-25-12.pdf.

5. M. Cirillo and B. Herbel-EISEnMAnN, "Mathematicians would say it this way." An investigation of teachers' framing of mathematicians, School Science and Mathematics 111 (2011), 68-77.

6. J. STIGLER and J. HiEBERT, The Teaching Gap, Simon \& Schuster, New York, 2000.

7. A. E. Austin, Promoting evidence-based change in undergraduate science education, paper commissioned by the National Academies National Research Council 
Board on Science Education, National Academy Press, Washington, DC, 2011.

8. L. DESLAURIERS, E. SCHELEW, and C. WIEMAN, Improving learning in a large enrollment physics class, Science 332 (2011), 862-864.

9. L. B. FliCK, P. SADRI, P. D. MORRELL, C. WAINWRIGHT, and A. SCHEPIGE, A cross discipline study of reform teaching by university science and mathematics faculty, School Science and Mathematics 109 (2009), 197-211.

10. C. RASMussen, K. MARRongelle, and O. N. KWON, A framework for interpreting inquiry oriented teaching, paper presented at the Annual Meeting of the American Educational Research Association, San Diego, CA, 2009.

11. C. WAinwright, P. D. Morrell, L. B. Flick, and A. SCHEPIGE, Observation of reform teaching in undergraduate level mathematics and science courses, School Science and Mathematics 104 (2004), 322-335.

12. A. E. Austin, Understanding and assessing faculty cultures and climates, in M. K. Kinnick (ed.), Providing
Useful Information for Deans and Department Chairs, Jossey-Bass, San Francisco, CA, 1995, pp. 47-63.

13. I Institutional and departmental cultures and the relationship between teaching and research, in J. Braxton (ed.), Faculty Teaching and Research: Is There a Conflict? Jossey-Bass, San Francisco, 1996, pp. 57-66.

14. E. L. BOYER, Scholarship Reconsidered: Priorities of the Professoriate, Carnegie Foundation for the Advancement of Teaching, Princeton, NJ, 1990.

15. A. Neumann, Professing to Learn: Creating Tenured Lives and Careers in the American Research University, The Johns Hopkins Press, Baltimore, MD, 2009.

16. A. E. AUSTIN and R. G. BALDWIN, Faculty motivation for teaching, in P. Seldin (ed.), Improving College Teaching, Anker Publishing Co., Boston, MA, 1995, pp. 37-47.

17. A. E. Austin, Creating a bridge to the future: Preparing new faculty to face changing expectations in a shifting context, Review of Higher Education 26 (2003), 119-144

\section{Book Review}

\section{Burden of Proof: A Review of Math on Trial}

\section{Reviewed by Paul H. Edelman}

\begin{tabular}{l}
\hline Math on Trial \\
Leila Schneps and Coralie Colmez \\
Basic Books, 2013 \\
US\$26.99, 272 pages \\
ISBN-13: $978-0465032921$
\end{tabular}

In Math on Trial, Leila Schneps and Coralie Colmez write about the abuse of mathematical arguments in criminal trials and how these flawed arguments "have sent innocent people to prison" (p. ix). Indeed, people "saw their lives ripped apart by simple mathematical errors." The purpose of focusing on these errors, despite mathematics' "relatively rare use in trials" (p. x), is "that many of the common mathematical fallacies that pervade

Paul H. Edelman is professor of mathematics and law at Vanderbilt University. His email address is pau1. ede1man@vanderbi1t.edu.

The author thanks Ed Cheng, Chris Slobogin, and Suzanna Sherry for helpful comments.

DOI: http://dx.doi.org/10.1090/noti1024 the public sphere are perfectly represented by these trials. Thus they serve as ideal illustrations of these errors and of the drastic consequences that faulty reasoning has on real lives" (p. x). The authors' strategy is to identify common mathematical errors and then illustrate how those errors arose in trials. They seek to accomplish two goals: first, to impress upon the general public the importance of being able to "distinguish whether the numbers brandished in our faces are legitimately providing information or being misused for dangerous ends"; second, "to identify the most important errors that have actually occurred" so that such mistakes can be eliminated in the future.

These are worthy if anodyne goals, and I would not dare argue against them. But the claims that Schneps and Colmez make are strong ones and prompt many questions. Do they adequately support their contention that mathematics has a "disastrous record of causing judicial error?" How influential are mathematical arguments, anyway? Are mathematical arguments more problematic 